\title{
Transformational Leadership,Organizational Climate and Work Motivation in Boosting Teachers' Performance
}

\author{
Ahmad Yani, Billy Tunas, M. Entang \\ Post Graduate Program, Universitas Pakuan Bogor, Indonesia
}

\begin{abstract}
This study analyzes the effect of Transformational Leadership, Organizational Climate and Work Motivation in Boosting Teachers' Performance when tested both individually and simultaneously. Transformational Leadership, Organizational Climate and Work Motivation are treated as independent variables that boost the level of Teachers' Performance as a dependent variable. The research was conducted on proportional randomly selected 316 public junior high school teachers in Bekasi, Indonesia. Using mix method, a sequential explanatory design is applied where quantitative come first. The study both quantitatively and qualitatively reveals that there is a positive significant relationship among variables under the following distribution of coefficient of correlation: Transformational Leadership to Teachers' Performance $=0.3994$, Organizational Climate to Teachers' Performance $=0.5599$, Work Motivation to Teachers' Performance $=0.7161$, and when tested together it produces coefficient of determination $=0.759$ indicating the existence of other $24.1 \%$ variables not including in the model affecting Teachers' Performance
\end{abstract}

Keywords: Transformational Leadership, Organizational Climate, Work Motivation, Teachers, Performance.

\section{INTRODUCTION}

Reliable and competitive human resources is a valuable asset for both government organizations and private sector that in their daily life always faced with the situation and conditions of intense competition in order to maintain the quality and survival of the organization. The existence of private parties in educational organizations is very helpful to the government because the government has not been fully able to facilitate the implementation of education. The existence of a private party that conducts education under government supervision and moves with the same education system and curriculum can be a benchmark as well as control over the quality of the organization and the quality of graduates produced by public educational institutions.

In this preliminary survey, the assessment was conducted by several principals of several teachers in the school as many as 30 teachers in Public Junior High School in city of Bekasi. The preliminary survey results that have been successfully recapitulated is presented on the following table.

Table 1, Preliminary Result of Public Junior High School Teachers in Bekasi City

\begin{tabular}{|c|l|c|}
\hline No. & \multicolumn{1}{|c|}{ Focus of Observation } & Percentage of Problematic Teachers \\
\hline$[1]$ & Teachers' working efficiency meets the SOP & 56.67 \\
\hline$[2]$ & The effectiveness of teacher work and education personnel & 56.67 \\
\hline$[3]$ & Results of work in accordance with the standards & 58.33 \\
\hline$[4]$ & Achieving targeted programs & 53.33 \\
\hline$[5]$ & Competitiveness & 55.00 \\
\hline
\end{tabular}

Based on the preliminary survey data above, the performance of teachers in the work environment of Education Department of Bekasi City is still low. Therefore it needs to be upgraded to a better stage. However, such improvements, especially in terms of performance improvement, teachers need enough time because it relates to various factors such as transformational leadership, individual climate organization, work motivation and so forth.

Therefore, research on teachers' performance, transformational leadership, organizational climate and work motivation is needed to provide guidance and reference for interested parties in maintaining and improving organizational performance in accordance with predetermined goals, which is the common goal of all organizations. 
The formulation of the problem is specifically formulated as follows:

1. Is there a relationship between transformational leadership and teacher performance?

2. Is there a relationship between organizational climate and teacher performance?

3. Is there a correlation between work motivation and teacher performance?

4. Is there a relationship of transformational leadership, organizational climate and work motivation simultaneously with teacher performance?

\section{LITERATURE REVIEW}

Beatman, et.al, (2000) states that performance is the ability and effort shown by a person. The performance factor consists of internal factors and external factors. Internal factor is a factor of ability and effort that comes from within a person while difficulty factor task and luck factor is an external factor. Rue and Byars (2007) suggest that performance refers to how well an employee meets the job requirements.

Schermerhorn (2005:) argues that performance is the proper use of resources to generate values for the achievement of organizational goals. Factors include a. Productivity (quantity and quality of work achieved), b. Effectiveness (way of achieving the set goals), and Efficiency (use of calculated resources). Colquitt et.al, (2009) states that performance is the value of worker behavior that contributes positively or negatively to the achievement of organizational goals. Task performance contains factors: a. Routine Task Performance - the work behavior of individuals who are routine / familiar, normal and the results can be predicted. b. Adaptive Task Performance - individual work behaviors that provide unique and new work results, and unpredictable results of its work, and c. Creative Task Performance -the individual's working behavior that develops new ideas to bring about something new and useful in achieving organizational goals.

Gibson et.al, (2006) argue that performance is the 'outcomes' of work that is in accordance with the objectives to be achieved by the organization. The factors: a. quality (conformity with standards), b.efficiency ('reasonable' cost), and c.effectiveness (performance level). Olusola (2011) states that job performance is the work of employees in order to achieve the goals of the organization. The results of employee work are quantitative and qualitative measures of work activities, job performance and achievement of job goals. Performance criteria include: a. efficiency and b. effectiveness in the level of achievement of job goals. Sakiru et.al, (2013) reinforce that performance can be seen as the results of work achieved by the individual after expending efforts.

Based on the description of theories about the performance of teachers it can be synthesized that the performance of teachers is the performance of teachers based on knowledge, attitudes, skills and motivation in empowering resources in a planned manner to achieve the target work of the organization. The indicators include: a. effectiveness b. work efficiency c. quality of work $d$. competitiveness and e. quantity of work.

Robbins and Judge (2015) argue that transformational leadership is a leadership that inspires followers to set aside personal interests for the good of the organization and has tremendous influence on his followers with the following indicators : a) giving vision and mission, and instilling pride, $b$ ) communicating high expectations, and delivering important goals simply; c) enhancing rationality and enhancing intelligence; d) giving special attention to the individual, and treating followers individually.

Schermerhorn et.al, (2005) put forward the theory of transformational leadership. Transformational leadership is a leadership that is able to expand and increase the interest of its followers to be able to do something beyond their own interests for the benefit and goodness of others. The scope of transformational leadership is: a) charismatic b) inspiration c) intellectual stimulation and d) individual consideration.

Bass (2006) defines that transformational leadership is a leader inspiring, developing and empowering followers in two ways: achieving great results and being able to develop leadership capacity. Bass further mentions the elements of transformational leadership include:

1) Idealized Influence: to describe a charismatic leader, in which there is a sense of love from subordinates, and subordinates feel confident under his leadership and foster an attitude of respect and trust in his subordinates. 
2) Inspirational Motivation. Leaders can communicate expectations of high expectations to subordinates, using symbols to focus efforts to achieve goals in a simple way.

3) Intellectual Stimulation. This element in leadership can be seen in a leader's ability to create, interpret, and elaborate the symbols that appear in life, inviting subordinates to think in new ways. Leaders are able to improve intelligence and problem solving thoroughly.

4) Individualized Consideration. A leader will pay attention to individual factors should not be generalized because of differences, interests and self-development are different from each other.

Based on the above description of the theory it can be synthesized that transformational leadership is the behavior of leaders who are knowledgeable, visionary, committed, able to cooperate actively, creatively in order to achieve organizational goals that have been determined. The indicators are: a) charismatic, b) attention to subordinates, c) motivational inspiration, d) intellectual stimulus.

Black (2008) argue that the school's organizational climate can be classified as open climate which portrays the organization with vigor and vitality; giving satisfaction to group members in fulfilling their needs. Leaders' actions are smooth and harmonious, both from the group and the leader. Group members are easy to get job satisfaction because they can accomplish tasks well, while personal needs are met. The main characteristic of such organizational climate is the fairness of the behavior of all members.

Steers (2005) suggests that factors affecting organizational climate in schools include: a. the task structure which is the level of detail of the methods used to carry out tasks within the organization. $b$. rewards and penalties imposed on employees. The same fate or treatment received by employees in the organization will encourage them to cooperate, c. centralized decisions, with centralized decisions on upper management, there will be unity of direction for employees in work, d. The emphasis on achievement which is the desire of superiors for subordinates to do the job well and contribute to the goals to be achieved in the organization, e. pressure on training and development, i.e efforts undertaken to improve the ability of employees in the organization, f. security and risks for employees in performing their duties, g. openness and closeness between individuals in the organization, either between employees with superiors, or between employees and other employees, h. status or position of a person in the organization, i. recognition and feedback related to the employee's limitations to know what the boss is saying, $\mathrm{j}$. competence and organizational flexibility associated with the achievement of organizational goals in a flexible and creative.

Organizational climate is expected to have a major impact on teacher productivity within the organization. Organization is a system of cooperation a group of people to achieve common goals. School is an organization consisting of elements of principals, teachers, administrative staff and students. The achievement of school goals depends on the relationship and cooperation and the elements. Stoner (2010) said the interaction of the interrelated elements in the organization will affect the organization's climate in the organization. Hoy and Miskel (2000) explain that climate is one of the characteristics that distinguish one organization with other organizations.

Based on the above theory, it can be synthesized that the organizational climate is the work atmosphere that occurs in the form of patterns of relationships between individuals within the organization for the realization of common goals with the following indicators: 1) openness in duty, 2) conductivity of work, 3) mutual respect for opinions and the work of others, and 4) consensus on mutual decisions, 5) familial interpersonal relationships.

According to Boldini (2004) motivation is a pure impulse that comes from within a person to be free to do something desirable. Steers et.al, (2004) stated that work motivation is the drive to do something better or more efficiently in solving problems to achieve perfection in tasks charged with the following factors: personal responsibility, receiving feedback, and achieving moderate goals.

Robinns (2003) defines work motivation as a process that calculates the intensity, direction and persistence of individuals achieve a goal. The factors are a. counting the direction intensity $b$. perseverance to reach the goal. The word "motive" is defined as the effort that drives someone to do something. Motives can be said as the driving force from within and within the subject to perform certain activities in order to achieve a goal. Starting from the word motive, then the motivation can be interpreted as a driving force that has become active. Motives become active at certain times, especially when the need to achieve goals is felt. 
Greenberg (2008) defines work motivation as a set of processes that arise, directly within a person and maintain his behavior in achieving goals.

Based on the description of theories about work motivation it can be synthesized that the motivation of work is a drive that moves and directs individuals or groups either internally or externally to achieve the goals set. The indicators are internal factors: a). responsible; b). self-development; c). independence; and external factors: d). interpersonal relationships e). trying to always give the best.

Based on the study of the theory described above, the following hypothesis is formulated:

1. There is a positive relationship between transformational leadership and teachers' performance.

2. There is a positive relationship between organizational climate and teachers' performance.

3. There is a positive relationship between work motivation and teachers' performance.

4. There is a positive relationship between transformational leadership, organizational climate, and work motivation simultaneously with the teachers' performance.

\section{Methodology}

This study applies Sequential Explanatory Design Mixed Method where quantitative study is ahead of qualitative study to examine the relationship between variables tested in the study using three independent variables through data obtained from questionnaires. The independent variable is transformational leadership $\left(\mathrm{X}_{1}\right)$, organizational climate, $\left(\mathrm{X}_{2}\right)$, and work motivation $\left(\mathrm{X}_{3}\right)$, while the dependent variable is the teachers' performance. (Y).

The relationship among variables in the study described in Fig.1 below:

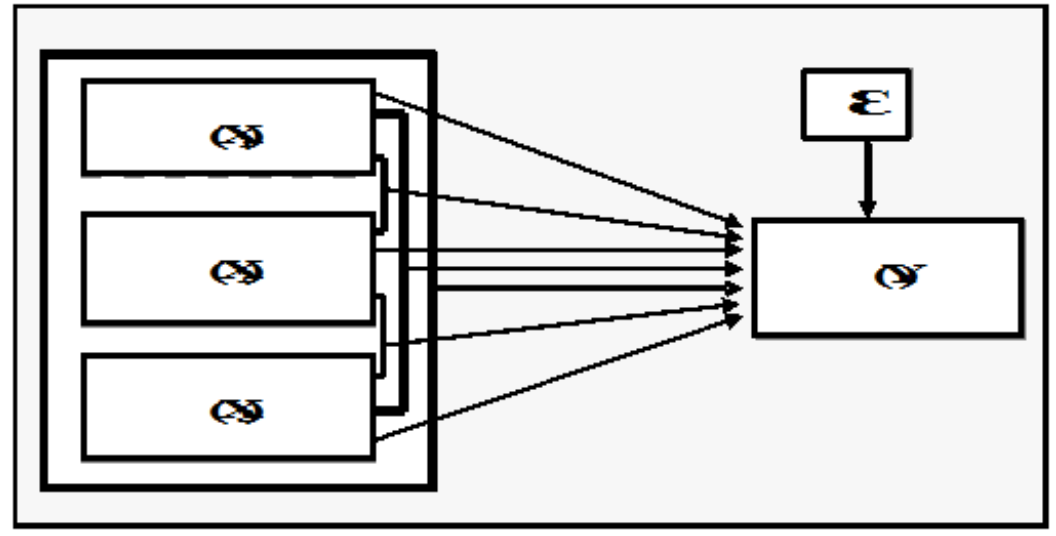

Figure1. Theoretical framework

Where,

$\mathrm{Y}=$ teachers' performance

$\mathrm{X}_{1}=$ transformational leadership

$\mathrm{X}_{2}=$ organizational climate

$\mathrm{X}_{3}=$ work motivation

The sampling technique is to count the number of samples by using the Taro Yamane's formula generating samples obtained as many as 316 respondents out of 1493 lecturers. Hypothesis testing is conducted by using regression analysis to determine the influence of one or more independent variables on the dependent variable. Hypothesis testing is performed at a significance level of 0.05 .

Qualitative study for the purpose of confirmation was performed through observation and interview to key informants as well as conducting focus group discussion with the principals of the schools and teachers.

\section{RESULT AND DISCUSSION}

The teachers of listed organizations were asked to participate in the survey by responding their opinions for four different measures in transformational leadership, organizational climate, work motivation, and the teachers' performance. 


\subsection{Transformational Leadership and Teachers' Performance}

Based on the results of hypothesis testing shows that there is a functional relationship between transformational leadership and teachers' performance with regression equation $\hat{Y}=88.867+0,3994$ $\mathrm{X}_{1}$ with value calculated- $\mathrm{F}=56.422>\mathrm{F}$ - table $(\alpha=0.05)=3.890$ which means that the regression is very significant.

The coefficient of determination between transformational leadership and teachers' performance is $=$ 0.1523 this means that $15.23 \%$ of teachers' performance is caused by transformational leadership while $84.77 \%$ is contributed by other variables that have a relationship with the increase of teachers' performance. The findings in this study indicate that transformational leadership is a leadership style that can create mutually motivating conditions between leaders and followers, so leaders can change followers to be better and creating a sense of trust and improving performance.

The findings in this study indicate that transformational leadership is a leadership style that can create mutually motivating conditions between leaders and followers, so leaders can change followers to be better and create a sense of trust and improve performance.

The above quantitative data is reinforced by observational data, interviews and documentation studies on qualitative research so that it can be concluded that transformational leadership conditions in each school observed has the same leadership form in accordance with the accompanying environment, so that the qualitative transformational leadership existing in the field has the same tendency with transformational leadership in quantitative terms.

This is in line with the theory of Schermerhorn et al, which suggests that transformational leadership is a leadership capable of expanding and enhancing the interest of followers to be able to do something beyond their own interests for the benefit and good of others. The scope of transformational leadership is: charismatic, inspiration, intellectual stimulation and individual consideration. Positive relationships in transformational leadership are how to empower members to become more potential and efficient to the organization, resulting in a good organizational performance supported by solid employee performance based on good awareness.

The results of this study support the previous research conducted by Sumirta Adhi (2013) entitled The Influence of Organizational Culture, Transformational Leadership and Work Motivation with Teacher Performance resulted in the conclusion that there is a relationship between transformational leadership to performance.

Based on the above description it can be concluded that the better the transformational leadership, the greater the performance of teachers. Thus the findings of facts and data in the analysis of this study further support the previous findings of a positive relationship between transformational leadership and performance.

\subsection{Organizational Climate and Teachers' Performance}

Based on the results of hypothesis testing shows that there is a functional relationship between organizational climate and teachers' performance with regression equation $\hat{Y}=64.489+0.5599 \mathrm{X}_{2}$ with value calculated- $\mathrm{F}=56.422>\mathrm{F}$ - table $(\alpha=0.05)=3.890$ which means that the regression is very significant.

The coefficient of determination between organizational climate and teachers' performance is $=$ 0.4193 this means that $41.93 \%$ of teachers' performance is caused by organizational climate while $58.07 \%$ is contributed by other variables that have a relationship with the increase of teachers' performance.

The findings obtained in this study indicate that the organizational climate is a set of working environment properties perceived workers either directly or indirectly in order to improve performance.

The above quantitative data is reinforced by observation data, interview and documentation study on qualitative research concluded the condition of organization climate in each school observed has pattern according to its confusion, so that the qualitative organization climate that exist in the field has the same tendency with organizational climate quantitatively. 
This is consistent with Gibson's theory that climate is a set of working environment properties perceived by workers either directly or indirectly. Positive relationship in organizational climate can support maximally implementation of organization program.

The results of previous research conducted by Brindusa Maria Popa (2011) resulted in the conclusion that the concept of organizational culture and climate used to describe the general characteristics of an organization on how to behave in relation to its members. Culture along with climate relations directly provides a link to organizational performance due to the fact that subjective attitudes and perceptions of the individual sometimes conflict with the norms set by the manager.

Based on the above description, it can be concluded that the better and conducive organizational climate then the teacher performance is also increasing. Thus the findings of facts and data in the analysis of this study further support the previous findings on the existence of a positive relationship between organizational climate and performance.

\subsection{Work Motivation and Teachers' Performance}

Based on the results of hypothesis testing shows that there is a functional relationship between work motivation and teachers' performance with regression equation $\hat{\mathrm{Y}}=43.361+0.7161 \mathrm{X}_{3}$ with value calculated- $\mathrm{F}=56.422>\mathrm{F}$ - table $(\alpha=0.05)=3.890$ which means that the regression is very significant.

The coefficient of determination between work motivation and teachers' performance is $=0.4162$ this means that $41.62 \%$ of teachers' performance is caused by work motivation while $58.38 \%$ is contributed by other variables that have a relationship with the increase of teachers' performance.

The findings obtained in this study indicate that the motivation of work is the provision of the driving force that creates the enthusiasm of one's work, so that they will cooperate, work effectively, and integrate all their efforts in order to improve performance.

The quantitative data above is reinforced by data of observation, interview and documentation study on qualitative research that conclude work motivation in each school observed has pattern and intensity of use which is adjusted to the needs and the environment, so that the qualitative has the same tendency with work motivation quantitatively.

This is in accordance with Boldini's theory of motivation as a pure impulse that comes from within a person to be free to do what is desired. A positive relationship in work motivation is the provision of driving force that creates the enthusiasm of one's work so that it can maximally support the implementation of the organization's program.

These findings support the results of previous research conducted by Sumirta Adhi (2013) that concluded that there is a relationship between work motivation with teacher performance.

Based on the above description it can be concluded that the better the work motivation, the greater the performance of teachers. Thus the findings of facts and data in the analysis of this study further support the previous findings on the existence of a positive relationship between work motivation and performance.

\subsection{Transformational Leadership, Organizational Climate, Work Motivation and Teachers' Performance}

The result of hypothesis testing shows that the functional relationship between 4.4 Transformational Leadership, Organizational Climate, Work Motivation and Teachers' Performance presented in the form of multiple regression equations: $\hat{Y}=305.49+0.539 \mathrm{X}_{1}+0.6368 \mathrm{X}_{2}+0.3493 \mathrm{X}_{3}$. Since the value of calculated-F $(702.821)$ is $>F_{\text {tabel }}(\alpha=0.05)=2.650$, it can be concluded that the relationship between transformational leadership, organizational climate, work motivation and teachers' performance is positive and significant. The result for the coefficient determination is 0.759 meaning that $75.90 \%$ variation of teachers' performance variable can be explained by variables of transformational leadership, organizational climate, and work motivation simultaneously while 24.10 $\%$ are determined by other variables that do not include in the model.

Another contributing factor of $24.10 \%$ was revealed through the focus of qualitative research. The findings of other factors that allegedly contributed to the achievement of such work based on observations, interviews and qualitative research documentation in the field are: 
1. Affordability of access; the school location is difficult to reach due to the lack of public transportation and is located in the outskirts of Bekasi.

2. HR gap; the ability of teachers in most Public Junior High Schools in Bekasi City has not been distributed evenly from the teacher's level of education, although there are many who have possessed bachelor degree but many of the educational backgrounds are not suitable.

3. Community Support; the community support is still low because most of the people in the capital city are mostly migrant communities with limited or varied education.

4. Organizational harmony; harmonious conditions in the organization need to be improved because the character of the urban population tends to be individualistic so it needs to be fostered with the program of togetherness / kinship in the organization.

The four factors outside the research variables above, causing the performance of teachers become choked up. Therefore, the need for immediate treatment in order to improve the performance of teachers can be more optimal and able to realize professional government apparatus, reliable and able to provide excellent service in every level of educational activities.

\section{CONCLUSION}

The results of the analysis shows that the statistical calculation of hypothesis testing and discussion of research results on relationship between transformational leadership, organizational climate, work motivation and performance of public junior high schools teachers in Bekasi City can be summarized as follows:

1. There is a positive significant relationship between transformational leadership and teacher performance.

2. There is a positive significant relationship between organizational climate and teacher performance.

3. There is a positive significant relationship between work motivation and teacher performance.

4. There is a positive significant relationship between transformational leadership, organizational climate and work motivation simultaneously with teacher performance.

Apart from the conclusions above, there are other factors that are related and contributed to the improvement of teacher performance revealed through qualitative interview: a. access affordability $b$. human resource gap. c. community support and d. organizational harmony.

\section{REFERENCES}

[1] Bass, Bernard M., Ronald E.Ringgio, 2006. Transformasional Leadership, Second Edition London: Laurence erlbuan Associates, Inc.,

[2] Brindusa Maria Popa, the Relationship between Performance and Organizational Climate, MSc, No 2 (2) / 2011. Regional Department of Defense Resources Management Studies, Brasov, Romania, Journal of Defense Resources Management.

[3] Boldini John, Great Motivation Secret of Greath Leader. 2004. New York: Mc Graw-Hill.

[4] Beatman, Thomas S., Derald R Ferris dan Stephen Strasser, 2000. Seri Ilmu dan Seri Manajemen Bisnis Kinerja, terjemahan Sofyan Cikmat, Jakarta, Alex Media Kompatindo.

[5] Black, G. L. (2008). A correlational analysis of servant leadership and school climate. University of Phoenix.

[6] Colquitt, Jason A. Jeffrey A.Lepine, Michael J.Wesson, 2009. Organizational Behavior Improving Performance and Commitment in the workplace, Boston: MeGraw-Hill/ lrwin.

[7] Gibson L., J.M Ivancevich, J.H. Donnelly., and R. Konopaske. 2006. Organizations: Behavior, Structure and Processes. New York: McGraw-Hill.

[8] Greenbeg Jerald dan Robert A. Baron. 2008. Behavior in Organizations, New Jersey: Pearson Education, Inc.

[9] Hoy, Wayne K, and Cicil G. Miskel, 2007. Educational Administration Theory Research and Practice, New York: Random House. 
[10] Olusola, O. 2011. Intrinsic Motivation, Job Satisfaction, and Self-Efficacy as Predictors of Job Performance of Industrial Workers in Ijebu Zone of Ogun State. The Journal of International Social Research, Vol. 4, Issue 17

[11] Robbins, Stephen P., and Timothy A. Judge. "Perilaku Organisasi Edisi 16." (2015).

[12] Robbins Stephen P., 2003. Organizational Behavior, New Jersey: Pearson Education, Inc.

[13] Rue Leslie W. dan Byars, 2007. Supervision Key Ling to Productivity, New York, Mc.Graw-Hill.

[14] Sakiru, O.K. , D.V. Enoho, S.D. Kareem, and M. Abdullahi. 2013. Relationship between employee performance, leadership styles and emotional intelligence in an organization. Journal of Humanities and Social Science (IOSR-JHSS), Volume 8, Issue 2, Jan. - Feb.

[15] Schermerhorn J.R., Jr. 2005. Management. New York: McGraw-Hill.

[16] Steers, Richard M, 2005. Efektifitas Organisasi, Edisi Revisi Terjemahan, Jakarta: Erlangga.

[17] Steers, R. M., Mowday, R. T., \& Shapiro, D. L. (2004). Introduction to special topic forum: The future of work motivation theory. The Academy of Management Review, 29(3), 379-387.

[18] Stoner. James A.F, 2010. Manajemen, London: Prentice Hall International Inc.

[19] Sumirta Adhi, 2013, the Effect of Organizational Culture, Transformational Leadership and Work Motivation toward Teacher Performance, Indian Journal of Positive Psycology, 4(4). hh. 537-539. 